\title{
Quality of Nursing Care Provided for Neonates on Mechanical Ventilation
}

\author{
Sabreen Abd Allah Mustafa ${ }^{1}$, Nafisa Hassan Refaat ${ }^{2}$, Fathia Zaki. Mohammed ${ }^{3}$ \& Nora Abd -El Hamid \\ Zaki ${ }^{4}$. \\ 1. Clinical demonstrator of Pediatric Nursing, Faculty of Nursing, Assiut University, Egypt. \\ 2. Professor of Pediatrics, Faculty of Medicine, Assiut University, Egypt. \\ 3. Assistant Professor of Pediatric Nursing, Faculty of Nursing, Assiut University, Egypt. \\ 4. Assistant Professor of Pediatric Nursing, Faculty of Nursing, Assiut University, Egypt.
}

\begin{abstract}
Background:-Mechanical ventilation plays an important role in reducing neonatal mortality and morbidity rate. Providing high-quality nursing care for neonates on mechanical ventilation help in improving health and wellbeing of neonates undergoing mechanical ventilation. So this study aimed to assess the quality of nursing care provided for neonates on mechanical ventilation. Research design, a descriptive research design was utilized in the current study. Sample. A convenience sampling of 59 nurses working at a neonatal intensive care unit in Assiut University Children Hospital. Two tools were used to collect the necessary data, interview questionnaire sheet, and observational checklists. Results of this study revealed that less than half $(47.5 \%)$ of the studied nurses had a good level of knowledge while more than one third (39\%) of them had a good level of care regarding the quality of nursing care provided for neonates on mechanical ventilation. There were no statistically significant differences between the total mean score of nurses' knowledge and practice $(\mathrm{P}=0.285)$. The study concluded that less than half of the nurses had a good level of knowledge and practice. So the researcher recommended that periodical educational training programs for nurses working at neonatal intensive care unit are mandatory for updating knowledge and to maintain an effective practice.
\end{abstract}

\section{Keywords: Quality of Nursing Care, Neonates \& Mechanical Ventilation.}

\section{Introduction}

Mechanical ventilation (MV) is an automatic device that provides all or part of the work of breathing for neonates who are impotent to breathe sufficiently on their own. The goal of mechanical ventilation is to maintain adequate pulmonary gas exchange, reduce the work of breathing and decrease exhaustion for neonates.

It is estimated that between $10 \%-20 \%$ of all neonates admitted to the Neonatal Intensive Care Unit receive mechanical ventilation. (Aurora et al., 2017).

Mechanical ventilation is used for neonates who suffer from insufficient ventilation and oxygenation in order to prevent atelectasis, collapsed lungs, provide alveolar ventilation, get rid of the accumulated carbon dioxide, increase lung volume, and to support and ease respirations in the neonate, reducing the work of breathing, and minimizing ventilator-induced lung injury. ( Sabzeie et al., 2016).

Quality of nursing care (QNC) is defined as "the degree of excellence in delivering the best possible care and achieving the best possible outcomes for people every time they deal with the healthcare system or use its services, also it is the grade to which health services for individuals and populations increase the likelihood of desired health outcomes and are steady with current professional knowledge. (Haruzivishe, 2016).
Quality improvement is a major focus of neonatal health care. It aims at refining neonatal health care outcomes and associated activities that contribute to neonatal care nurses, as the principal caregivers in each health care system, directly and profoundly affect the lives of neonates and are critical to the quality of care neonates receive. (Ahmed, 2014).

Each nurse is responsible for her own quality of performance and is accountable for the use of standards to ensure knowledge, safe and comprehensive nursing care providing for a neonate on mechanical ventilation. Therefore to improve the quality of neonatal nursing care and enhance the role of the nurse in providing quality services to neonates, nurses should undergo a series of lectures and practical training courses to improve the health and wellbeing of neonates. (American Nurses Association., 2010).

Nurses play an important role in providing routine nursing care for neonates on mechanical ventilation as observing the monitor, ventilation devices, oxygen delivery systems, neonate's oxygenation, thermoregulation, optimal positioning, airway clearance, stable hemodynamic status and adequate nutrition for maintenance of growth and development for these neonates. (Kalia, 2015). 


\section{Significance of the study}

The neonatal period is a highly vulnerable time for a neonate who is competing for numerous of the physiologic adjustments necessary for extrauterine existence. The neonatal mortality rate reflects not only the quality of care accessible to women during pregnancy but also the quality of care available to neonates throughout the first month of life. The leading reasons of mortality rate during the first 4 weeks of life are prematurity, respiratory distress syndrome and congenital malformation, nearly $80 \%$ of neonates who die within 48 hours after birth are Very Low Birth Weight (VLBW) or Extremely Low Birth Weight (ELBW), these not require only immediate diagnosis and treatment, but also continue skilled nursing care. Mechanical ventilation has become a necessity to enhance neonatal survival rate and is an essential component of neonatal intensive care units. (Ahmed, 2014) So this study was conducted to assess the quality of nursing care provided for neonates on mechanical ventilation.

\section{Aim of the Study}

\section{This study aimed to}

Assess the quality of nursing care provided for neonates on mechanical ventilation.

\section{Research questions}

1- Do nurses provide competent nursing care for neonates on mechanical ventilation?

2- Do nurses have a good level of knowledge regarding the quality of nursing care for neonates on mechanical ventilation?

3- Are there relations between nurses' knowledge and performance?

\section{Subjects \& Method \\ A- Research design}

A descriptive research design was used to conduct this study.

\section{B- Setting}

This study was conducted at Neonatal Intensive Care Unit (NICU) in Assiut University Children Hospital.

\section{C- Subjects}

A convenience sampling of 59 nurses participated in the current study.

Tools of data collection

Two tools were used to gather the necessary data

Tool (1): Interview Questionnaire sheet

It was developed by the researcher after reviewing related literature to assess nurses' knowledge about nursing care for neonates on mechanical ventilation and it included two parts

\section{Part (I)}

a- Personal characteristics of the studied nurses that include age, marital status, qualification, residence, years of experience and attending previous training program (questions 1-6).

b- Demographic and clinical data of neonates on mechanical ventilation such as age on admission, gestational age at birth, birth weight and medical diagnosis.

Part (II): Nurses' knowledge about mechanical ventilation such as (definition, indications, complications, indicators of weaning from mechanical ventilation, as well as nurses' knowledge regarding the quality of nursing care for a neonate on mechanical ventilation) there were 20 questions.

\section{Tool (2): Observational checklists Sheet}

The observation checklists sheet which was developed by the researcher based on related pediatric nursing procedures manual (Taksande, 2014 \& Kalia, 2015). It was used to assess the quality of nursing care for the neonates on mechanical ventilation. It included the procedures of hand washing, axillary temperature, endotracheal tube suctioning, chest physiotherapy (postural drainage and chest percussion \& vibration), intravenous infusion (cannula connection \& infusion steps), mouth care, eye care and positioning of a neonate, (all observed items of practice were 8 procedures).

\section{Scoring system for knowledge and practice}

- Scoring system for knowledge of the studied nurses was calculated as the following: the total number of questions was (20) questions and the total score of (40) were given for knowledge. Where (2) scores were given for completely correct answer, (1) for an incompletely correct answer, and (0) for do not know.

- Regarding nurses' practice, the total score of nurses' practice was 238 for all the nursing procedures carried out for the neonates on mechanical ventilation (119 items for the above-mentioned procedures). The nurses' practice was classified into either completely done (2), incompletely done (1), and not done (0). According to the nurses' responses, their level of knowledge and practice was categorized as the following: good level $(75 \leq$ $100 \%)$; average level $(60<75 \%)$ and poor level (<60\%) Ahmed, (2014).

- Data collection: An official permission was obtained from the director of the Neonatal Intensive Care Unit (NICU) in Assiut University Children Hospital to collect the necessary data for this study.

- A pilot study: was carried out on $10 \%$ of nurses (6 nurses) to test the clarity and applicability of the sheet and to estimate the time needed to fulfill each sheet. The data obtained from the pilot study were analyzed; no change was done in the questions, so they were included in the study.

- Validity: The validity of the tool was tested by measuring its Content Validity Index (CVI) by 5 
experts in both pediatric nursing and neonatologist field and it's equaled 93\%.

- Reliability test was done using alpha Cronbach's test and it's equaled $(r=0.79)$.

Field of the work

This study was carried out through a period of four months from (the beginning of November 2018 to the end of Feberarury 2019). It was done every other day at NICU. Interviewing of studied nurses were conducted according to their available time in the morning shift to collect data; two or three nurses were interviewed per day. The time needed for each interview questioner sheet ranged from 15-20 minutes according to the response of the participant nurses. Indirect observation for nursing practice regarding neonates on mechanical ventilation was done individually for each nurse. The time needed for observing every each nurse ranged from 1-2 hours. From 1-2 nurses were observed per day.

\section{Results}

Table (1): Characteristics of studied nurses' $(n=59)$.

\section{Table (1). Characteristics of studied nurses' (n=59).}

\begin{tabular}{|c|c|c|}
\hline Items & $(n=59)$ & $\%$ \\
\hline \multicolumn{3}{|l|}{ Age: (years) } \\
\hline$<30$ & 37 & 62.7 \\
\hline$\geq 30$ & 22 & 37.3 \\
\hline Mean \pm SD & \multicolumn{2}{|c|}{$28.44 \pm 5.31$} \\
\hline \multicolumn{3}{|l|}{ Residence: } \\
\hline Rural & 43 & 72.9 \\
\hline Urban & 16 & 27.1 \\
\hline \multicolumn{3}{|l|}{ Marital status: } \\
\hline Single & 22 & 37.3 \\
\hline Ever -married & 37 & 62.7 \\
\hline \multicolumn{3}{|l|}{ Qualifications: } \\
\hline Bachelor of nursing & 5 & 8.5 \\
\hline Technical health institute & 4 & 6.8 \\
\hline Technical nursing institute & 15 & 25.4 \\
\hline Secondary school of nursing & 35 & 59.3 \\
\hline \multicolumn{3}{|l|}{ Years of experience: } \\
\hline$<5$ & 22 & 37.3 \\
\hline $5-<10$ & 3 & 5.1 \\
\hline $10-<15$ & 25 & 42.4 \\
\hline$\geq 15$ & 9 & 15.2 \\
\hline Mean \pm SD & \multicolumn{2}{|c|}{$9.15 \pm 6.61$} \\
\hline \multicolumn{3}{|c|}{ Did you attend a training program about the quality of care for neonates on mechanical ventilation? } \\
\hline Yes & 1 & 1.7 \\
\hline No & 58 & 98.3 \\
\hline
\end{tabular}

\section{Ethical considerations}

The research proposal was approved from the Ethical Committee in the Faculty of Nursing. There was no risk for study subject during application of the research. Written consent was taken from all nurses to participate in the study. The purpose and nature of the study were explained by the researcher through direct personal communication prior to starting their participation in the study. These data were confidential between nurses and the researcher and used for the purpose of the research only.

Statistical analysis

Data entry and data analysis were done using SPSS version 19 (Statistical Package for Social Science). Data were presented as a number, percentage, mean and standard deviation. Chi-square test was used to compare qualitative variables. Pearson correlation was done to measure the correlation between quantitative variables. P-value was considered statistically significant when $\mathrm{P}<0.05$. 
Table (2): Characteristics of studied neonates' $(n=59)$.

\begin{tabular}{|c|c|c|}
\hline Items & $(n=59)$ & $\%$ \\
\hline \multicolumn{3}{|l|}{ Age on admission/ days: } \\
\hline$<1$ & 29 & 49.2 \\
\hline $1-<7$ & 23 & 39.0 \\
\hline$\geq 7$ & 7 & 11.8 \\
\hline \multicolumn{3}{|l|}{ Gestational age at birth/ weeks: } \\
\hline $28-<32$ & 12 & 20.4 \\
\hline $32-<36$ & 30 & 50.8 \\
\hline $36-40$ & 17 & 28.8 \\
\hline Mean \pm SD & \multicolumn{2}{|c|}{$33.80 \pm 3.07$} \\
\hline \multicolumn{3}{|l|}{ Birth weight/gm } \\
\hline$<1000$ & 2 & 3.4 \\
\hline $1000-$ & 4 & 6.8 \\
\hline $1500-$ & 20 & 33.9 \\
\hline $2500-$ & 17 & 28.8 \\
\hline$\geq 3000$ & 16 & 27.1 \\
\hline Mean \pm SD & \multicolumn{2}{|c|}{$2420.8 \pm 731.5$} \\
\hline \multicolumn{3}{|l|}{ Diagnosis: } \\
\hline Respiratory distress syndrome & 29 & 49.2 \\
\hline Congenital anomalies & 20 & 33.8 \\
\hline Pneumonia & 10 & 17.0 \\
\hline
\end{tabular}

Table (3): Number and percentage distribution of the studied nurses' knowledge regarding the quality of care for neonates on mechanical ventilation $(n=59)$

\begin{tabular}{|c|c|c|c|c|c|c|}
\hline \multirow{2}{*}{ Items } & \multicolumn{2}{|c|}{ Correct } & \multicolumn{2}{|c|}{ Incorrect } & \multicolumn{2}{|c|}{ Don't know } \\
\hline & No. & $\%$ & No & $\%$ & No & $\%$ \\
\hline $\begin{array}{l}\text { Definition of mechanical ventilation: (is the process of gas exchange, an apparatus } \\
\text { that facilitate the transport of } \mathrm{O}_{2} \text { and } \mathrm{CO}_{2} \text { between the atmosphere and the alveoli or } \\
\text { device of transport feeding to the stomach). }\end{array}$ & 48 & 81.4 & 9 & 15.3 & 2 & 3.3 \\
\hline $\begin{array}{l}\text { Indications of mechanical ventilation such as (respiratory insufficiency in neonates } \\
\text { especially in preterm, gastrointestinal tract disorders in neonates or sleep disorders } \\
\text { in neonates). }\end{array}$ & 51 & 86.4 & 0 & 0.0 & 8 & 13.6 \\
\hline $\begin{array}{l}\text { The most common complications of mechanical ventilation such as (ventilator- } \\
\text { associated pneumonia, obstruction of an endotracheal tube or air leak from the } \\
\text { tube). }\end{array}$ & 23 & 39.0 & 35 & 59.3 & 1 & 1.7 \\
\hline $\begin{array}{l}\text { How to prevent nosocomial infection in mechanically ventilated neonates through } \\
\text { (hand washing before and after dealing with the neonate, cleaning thermometer or } \\
\text { applying chest physiotherapy). }\end{array}$ & 55 & 93.2 & 1 & 1.7 & 3 & 5.1 \\
\hline $\begin{array}{l}\text { How to maintain airway patent in mechanically ventilated neonates through (place } \\
\text { the neonate in semi setting position and head midline, place the neonate lateral } \\
\text { position or head flexed forward). }\end{array}$ & 53 & 89.8 & 5 & 8.5 & 1 & 1.7 \\
\hline $\begin{array}{l}\text { The best time for endotracheal tube (ETT) suction to be done (before feeding, } \\
\text { after feeding or before administration of medications). }\end{array}$ & 55 & 93.2 & 2 & 3.4 & 2 & 3.4 \\
\hline $\begin{array}{l}\text { When do you do endotracheal suction for mechanically ventilated neonates } \\
\text { (according to neonate's condition, every two hours or every shift)? }\end{array}$ & 51 & 86.4 & 8 & 13.6 & 0 & 0.0 \\
\hline $\begin{array}{l}\text { The best time to perform chest physiotherapy for mechanically ventilated neonates } \\
\text { (before suction, after feeding or before sleeping). }\end{array}$ & 57 & 96.6 & 1 & 1.7 & 1 & 1.7 \\
\hline $\begin{array}{l}\text { How do you assess the signs of adequate ventilation in mechanically ventilated } \\
\text { neonates (noting neonate's color, observe spontaneous breathing or follow intake } \\
\text { and output)? }\end{array}$ & 38 & 64.4 & 21 & 35.6 & 0 & 0.0 \\
\hline $\begin{array}{l}\text { Signs of adequate ventilation in mechanically ventilated neonates such as (oxygen } \\
\text { saturation more than } 90 \% \text {, irregular respiratory rate or regular intake and output). }\end{array}$ & 56 & 94.9 & 3 & 5.1 & 0 & 0.0 \\
\hline $\begin{array}{l}\text { Signs of inadequate ventilation in mechanically ventilated neonates such as } \\
\text { (regular respiration, cyanosis or regular heart rate). }\end{array}$ & 57 & 96.6 & 2 & 3.4 & 0 & 0.0 \\
\hline
\end{tabular}


Table (3): Continue, number and percentage distribution of the studied nurses' knowledge regarding the quality of care for neonates on mechanical ventilation $(n=59)$

\begin{tabular}{|c|c|c|c|c|c|c|}
\hline \multirow[b]{2}{*}{ Items } & \multicolumn{2}{|c|}{ Correct } & \multicolumn{2}{|c|}{ Incorrect } & \multicolumn{2}{|c|}{ Don't know } \\
\hline & No & $\%$ & No & $\%$ & No & $\%$ \\
\hline $\begin{array}{l}\text { The routine method of measuring body temperature for mechanically } \\
\text { ventilated neonates such as (oral method, axillary method or rectal } \\
\text { method). }\end{array}$ & 59 & 100.0 & 0 & 0.0 & 0 & 0.0 \\
\hline $\begin{array}{l}\text { How to maintain body temperature within normal for mechanically } \\
\text { ventilated neonates (pre-warmed incubator, don't open incubator or } \\
\text { don't use air condition). }\end{array}$ & 55 & 93.2 & 4 & 6.8 & 0 & 0.0 \\
\hline $\begin{array}{l}\text { How to perform eye care for mechanically ventilated neonates (gently } \\
\text { swab from the inner canthus to the outer canthus of the eye, put cold } \\
\text { compresses or put hot compresses). }\end{array}$ & 59 & 100.0 & 0 & 0.0 & 0 & 0.0 \\
\hline $\begin{array}{l}\text { How to prevent ventilator-associated pneumonia in mechanically } \\
\text { ventilated neonates through (hand washing and apply gloves, } \\
\text { oropharyngeal suction, and oral care or give antibiotics). }\end{array}$ & 28 & 47.5 & 29 & 49.2 & 2 & 3.3 \\
\hline $\begin{array}{l}\text { How to prevent oral ulcers in mechanically ventilated neonates through } \\
\text { (change the site of ETT from side to another, drying of mouth or daily } \\
\text { change tube fixation). }\end{array}$ & 33 & 55.9 & 23 & 39.0 & 3 & 5.1 \\
\hline $\begin{array}{l}\text { How to prevent pressure sores in mechanically ventilated neonates } \\
\text { through (change position every 2hours, follow intake and output or } \\
\text { don't massage skin). }\end{array}$ & 59 & 100.0 & 0 & 0.0 & 0 & 0.0 \\
\hline $\begin{array}{l}\text { How to assess the general condition of mechanically ventilated } \\
\text { neonates through (taking vital signs every } 2 \text { hours, follow intake and } \\
\text { output every } 36 \text { hours or taking the length of neonates). }\end{array}$ & 43 & 72.9 & 6 & 10.2 & 10 & 16.9 \\
\hline $\begin{array}{l}\text { How to follow up the growth of the mechanically ventilated neonates } \\
\text { through (weight neonate, monitor intake and output or measuring vital } \\
\text { signs). }\end{array}$ & 54 & 91.5 & 4 & 6.8 & 1 & 1.7 \\
\hline $\begin{array}{l}\text { Indicators of weaning from mechanical ventilation such as (when } \\
\text { neonate able to be fed, able to take spontaneous breathing or increase in } \\
\text { weight and length of neonate). }\end{array}$ & 56 & 94.9 & 2 & 3.4 & 1 & 1.7 \\
\hline Mean \pm SD & & & 17.12 & & & \\
\hline
\end{tabular}

Table (4): Number and percentage distribution of the studied nurses' practice provided for neonates on mechanical ventilation $(\mathbf{n}=59)$.

\begin{tabular}{|l|c|c|c|c|c|c|c|}
\hline \multirow{2}{*}{ Items } & \multirow{2}{*}{ Total score } & \multicolumn{2}{c|}{ Completely done } & \multicolumn{2}{c|}{$\begin{array}{c}\text { Incompletely } \\
\text { done }\end{array}$} & \multicolumn{2}{c|}{ Not done } \\
\cline { 3 - 8 } & & No. & $\mathbf{\%}$ & No & \% & No & \% \\
\hline \hline Hand washing & $12.83 \pm 2.17$ & $\mathbf{4 8}$ & $\mathbf{8 1 . 4}$ & 6 & 10.1 & 5 & 8.5 \\
\hline Taking an axillary temperature & $22.81 \pm 3.45$ & $\mathbf{3 1}$ & $\mathbf{5 2 . 5}$ & 23 & 39.0 & 5 & 8.5 \\
\hline Endotracheal tube (ET) suctioning & $35.64 \pm 3.31$ & $\mathbf{5 0}$ & $\mathbf{8 4 . 7}$ & 7 & 11.9 & 2 & 3.3 \\
\hline Chest physiotherapy & $34.73 \pm 5.45$ & $\mathbf{3 4}$ & $\mathbf{5 7 . 6}$ & 18 & 30.5 & 7 & 11.9 \\
\hline Intravenous infusion & $43.46 \pm 5.17$ & $\mathbf{4 2}$ & $\mathbf{7 1 . 2}$ & 15 & 25.4 & 2 & 3.4 \\
\hline Mouth care & $11.25 \pm 2.33$ & $\mathbf{3 9}$ & $\mathbf{6 6 . 1}$ & 11 & 18.6 & 9 & 15.3 \\
\hline Eye care & $13.54 \pm 2.30$ & $\mathbf{3 0}$ & $\mathbf{5 0 . 8}$ & 20 & 33.9 & 9 & 15.3 \\
\hline The positioning of the neonate & $11.32 \pm 3.15$ & 18 & 30.5 & $\mathbf{2 5}$ & $\mathbf{4 2 . 4}$ & 16 & 27.1 \\
\hline \multicolumn{1}{|c|}{} & & $\mathbf{1 8 5 . 5 9} \pm \mathbf{2 0 . 3 5}$ & & \\
\hline
\end{tabular}

Table (5): Relation between total nurses' level of knowledge and their personal data. $(n=59)$.

\begin{tabular}{|c|c|c|c|c|c|c|c|}
\hline \multirow{3}{*}{ Items } & \multicolumn{6}{|c|}{ Knowledge level } & \multirow{3}{*}{ P-value } \\
\hline & \multicolumn{2}{|c|}{ Poor } & \multicolumn{2}{|c|}{ average } & \multicolumn{2}{|c|}{ Good } & \\
\hline & No. & $\%$ & No. & $\%$ & No. & $\%$ & \\
\hline \multicolumn{7}{|l|}{ Age: (years) } & \multirow{3}{*}{0.209} \\
\hline$<30$ & 9 & 24.3 & 10 & 27.1 & 18 & 48.6 & \\
\hline$\geq 30$ & 2 & 9.0 & 10 & 45.5 & 10 & 45.5 & \\
\hline \multicolumn{7}{|l|}{ Residence: } & \multirow{3}{*}{$0.018^{*}$} \\
\hline Rural & 9 & 20.9 & 10 & 23.3 & 24 & 55.8 & \\
\hline Urban & 2 & 12.5 & 10 & 62.5 & 4 & 25.0 & \\
\hline \multicolumn{7}{|l|}{ Marital status: } & \multirow{3}{*}{0.144} \\
\hline Single & 5 & 22.7 & 4 & 18.2 & 13 & 59.1 & \\
\hline Ever-married & 6 & 16.2 & 16 & 43.3 & 15 & 40.5 & \\
\hline
\end{tabular}




\begin{tabular}{|c|c|c|c|c|c|c|c|}
\hline \multirow{3}{*}{ Items } & \multicolumn{6}{|c|}{ Knowledge level } & \multirow{3}{*}{ P-value } \\
\hline & \multicolumn{2}{|c|}{ Poor } & \multicolumn{2}{|c|}{ average } & \multicolumn{2}{|c|}{ Good } & \\
\hline & No. & $\%$ & No. & $\%$ & No. & $\%$ & \\
\hline \multicolumn{7}{|l|}{ Qualifications: } & \multirow{3}{*}{$0.034 *$} \\
\hline Bachelor/ nursing institute & 8 & 33.4 & 5 & 20.8 & 11 & 45.8 & \\
\hline Secondary school of nursing & 3 & 8.5 & 15 & 42.9 & 17 & 48.6 & \\
\hline \multicolumn{7}{|l|}{ Years of experience: } & \multirow{3}{*}{$0.036^{*}$} \\
\hline$<10$ & 8 & 32.0 & 5 & 20.0 & 12 & 48.0 & \\
\hline$\geq 10$ & 3 & 8.8 & 15 & 44.1 & 16 & 47.1 & \\
\hline
\end{tabular}

*Statistically significant differences at p. value $<0.05$

Table (6): Relation between total nurses' level of practice and their personal data $(n=59)$.

\begin{tabular}{|c|c|c|c|c|c|c|c|}
\hline \multirow{3}{*}{ Items } & \multicolumn{6}{|c|}{ practice level } & \multirow{3}{*}{ P-value } \\
\hline & \multicolumn{2}{|c|}{ Poor } & \multicolumn{2}{|c|}{ average } & \multicolumn{2}{|c|}{ Good } & \\
\hline & No. & $\%$ & No. & $\%$ & No. & $\%$ & \\
\hline Age: (years) & & & & & & & \multirow{3}{*}{0.094} \\
\hline$<30$ & 12 & 32.5 & 11 & 29.7 & 14 & 37.8 & \\
\hline$\geq 30$ & 2 & 9.1 & 11 & 50.0 & 9 & 40.9 & \\
\hline \multicolumn{7}{|l|}{ Residence: } & \multirow{3}{*}{0.105} \\
\hline Rural & 13 & 30.2 & 16 & 37.2 & 14 & 32.6 & \\
\hline Urban & 1 & 6.2 & 6 & 37.6 & 9 & 56.2 & \\
\hline \multicolumn{7}{|l|}{ Marital status: } & \multirow{3}{*}{$0.034^{*}$} \\
\hline Single & 9 & 40.9 & 8 & 36.4 & 5 & 22.7 & \\
\hline Ever-married & 5 & 13.6 & 14 & 37.8 & 18 & 48.6 & \\
\hline \multicolumn{7}{|l|}{ Qualifications: } & \multirow{3}{*}{$0.012^{*}$} \\
\hline Bachelor/ nursing institute & 10 & 41.7 & 9 & 37.5 & 5 & 20.8 & \\
\hline Secondary school of nursing & 4 & 11.5 & 13 & 37.1 & 18 & 51.4 & \\
\hline \multicolumn{7}{|l|}{ Years of experience: } & \multirow{3}{*}{$0.011^{*}$} \\
\hline$<10$ & 10 & 40.0 & 10 & 40.0 & 5 & 20.0 & \\
\hline$\geq 10$ & 4 & 11.8 & 12 & 35.3 & 18 & 52.9 & \\
\hline
\end{tabular}

*Statistically significant differences at p. value $<0.05$

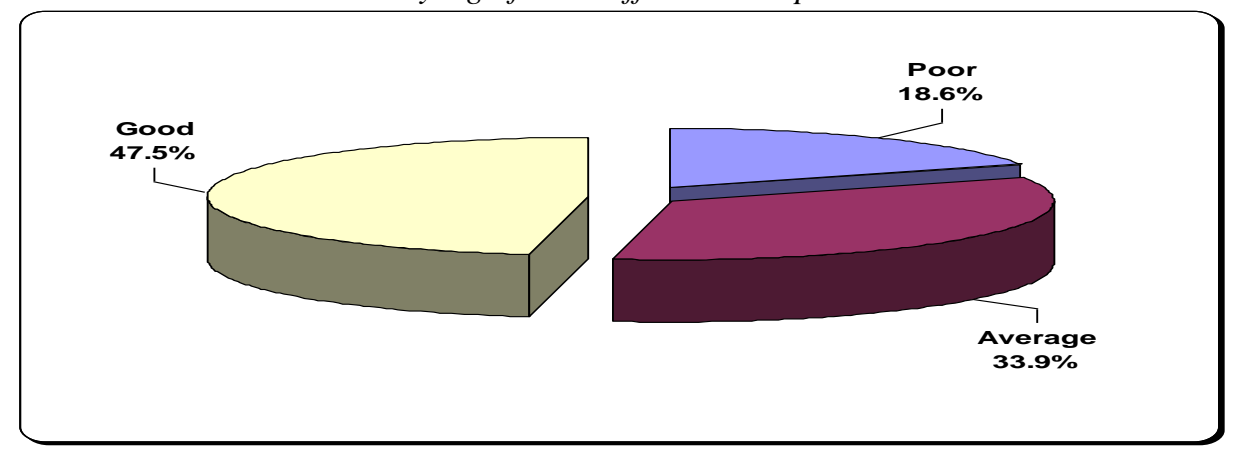

Figure (1): level of knowledge of studied nurses regarding the quality of nursing care for neonates on mechanical ventilation.

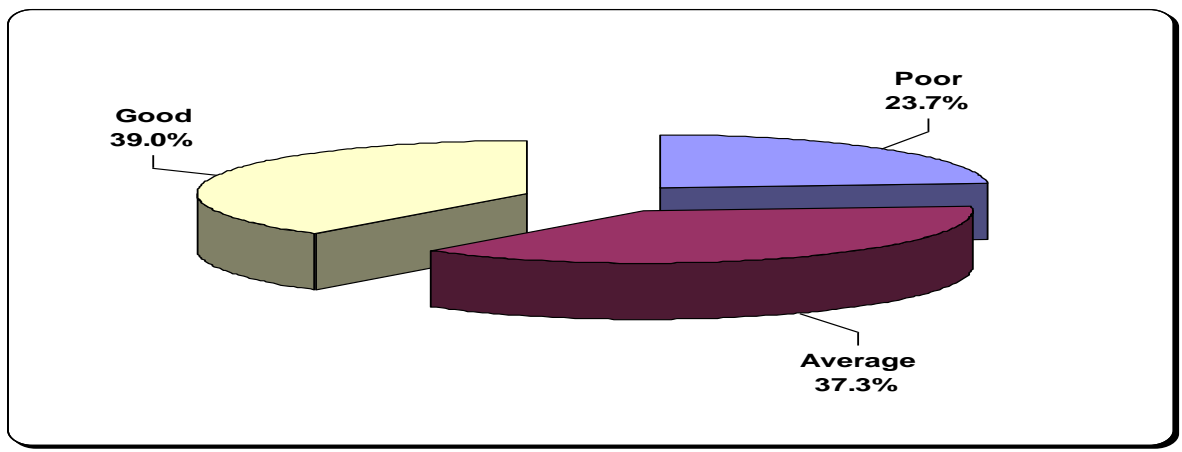

Figure (2): level of practice of studied nurses provided for neonates on mechanical ventilation. 


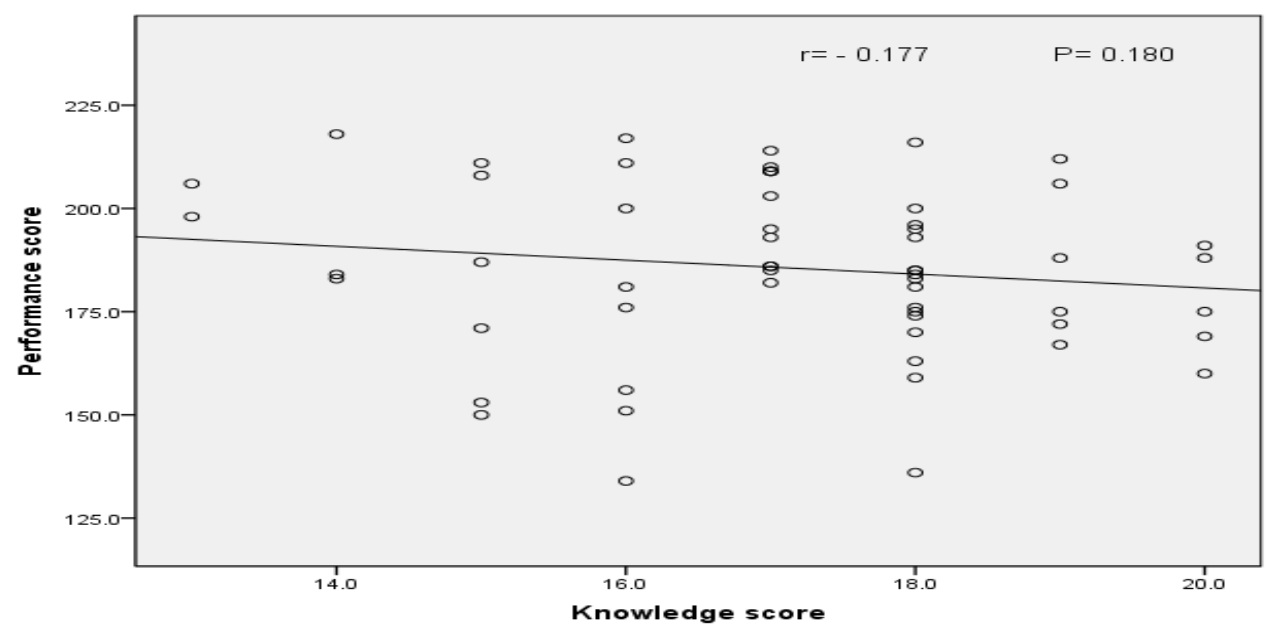

Figure (3): Relation between the total score of the studied nurses' knowledge and practice regarding care of neonates on mechanical ventilation.

It was clear from Table (1): That less than two thirds $(62.7 \%)$ of the studied nurses' were less than 30 years with a mean age of $28.44 \pm 5.31$. years Less than three quarters $(72.9 \%)$ of them were from rural areas, more than half $(57.6 \%)$ of them were ever married. Apparently from the same table that more than half $(59.3 \%)$ of the studied nurses graduated from secondary school of nursing. $42.4 \%$ of them were 10 $<15$ years' experience in caring for a neonate on mechanical ventilation and the vast majority $(98.3 \%)$ of them didn't attend a training program.

Table (2): Reveals that the distribution of neonatal characteristics whereas less than half $(49.2 \%)$ of the neonates their age was less than 1 day. More than half $(50.8 \%)$ of the neonates had gestational age from 32-36 weeks, with mean \pm SD of $33.80 \pm 3.07$ weeks and $(33.9 \%)$ of them had birth weight from 1500 - < $2500 \mathrm{gm}$ with mean \pm SD $2420 \pm 0.73 \mathrm{gm}$. while less than half $(49.2 \%)$ of them diagnosed with respiratory distress syndrome.

Table (3): Illustrates that all of the studied nurses $(100 \%)$ had correct answer related to the routine method for measuring body temperature for neonates on mechanical ventilation, providing eye care and how to prevent pressure sore in mechanically ventilated neonates.

As regard to the studied nurses' level of knowledge about quality of care for neonates on mechanical ventilation it was found that most of them $(91.5 \%$, $93.2 \%, 93.2 \%, 93.2 \%, 94.9 \%, 94.9 \%, 96.6 \%, 96.6 \%$ respectively) of them had correct answer regarding to follow up the growth of the mechanically ventilated neonates, how to prevent nosocomial infection in mechanically ventilated neonates, the best time of endotracheal suction to be done, maintain body temperature within normal level for mechanically ventilated neonates, what are signs of adequate ventilation in mechanically ventilated neonates, signs of weaning from mechanical ventilation, the best time to perform chest physiotherapy for mechanically ventilated neonates and what are signs of inadequate ventilation in mechanically ventilated neonates.

The results revealed that the vast majority $(81.4 \%$, $86.4 \% \& 89.8 \%$ ) of the studied nurses had correct answer related to the definition of mechanical ventilation, indications of mechanical ventilation and how to maintain a patent airway in mechanically ventilated neonates. while more than half $(59.3 \%)$ of them had incorrect answer related to the most common complications of mechanical ventilation.

More than two thirds $(72.9 \%)$ of the studied nurses had correct answer related to how to assess the general condition of mechanically ventilated neonates. while $(64.4 \%)$ of them had correct answer related to how to assess signs of adequate ventilation in mechanically ventilated neonates, while less than half $(47.5 \%)$ of them know how to prevent ventilatorassociated pneumonia in mechanically ventilated neonates. More than half $(55.9 \%$ \& $51 \%)$ of them had correct answer related to how to prevent oral ulcer in mechanically ventilated neonates and when do you do endotracheal suction for mechanically ventilated neonates.

Table (4): Presents the number and percentage distribution of the studied nurses' practice provided for neonates on mechanical ventilation. It was found that the majority $(81.4 \%$ and $84.7 \%$ respectively) of them had a good level of practice related to hand washing and endotracheal tube suctioning. More than half $(50.8 \%, 52.5 \%$, and $57.6 \%$ respectively) of them 
had a good level of practice related to eye care, taking an axillary temperature and chest physiotherapy and more than two thirds $(66.1 \%$ and $71.2 \%$ respectively) of them had good level of practice related to mouth care and Intravenous infusion, while less than half $(42.4 \%)$ of them had average level of practice related to positioning of the neonate.

It is noticed that there were statistically significant differences between total score of the studied nurses' level of knowledge according to their personal data such as residence, educational level and years of experience $\quad(\mathrm{P}<0.018, \quad \mathrm{P}<0.034 \quad \& \mathrm{P}<0.036$ respectively). On the other hand, no statistically significant differences regarding age and marital status $(\mathrm{P}=0.209 \& \mathrm{P}=0.144)$ as shown in table (5). It was observed that there were statistically significant differences between total score of the studied nurses' level of practice according to their personal data such as marital status, educational level and years of experience ( $\mathrm{P}<0.034, \mathrm{P}<0.012 \&$ $\mathrm{P}<0.011$ respectively). However, no statistically significant differences were found regarding age and residence $(\mathrm{P}=0.094 \& \mathrm{P}=0.105)$, as clarified in a table (6).

Figure (1): Indicates the level of knowledge of studied nurses regarding the quality of nursing care provided for neonates on mechanical ventilation. It was found that more than half $(47.5 \%)$ of the studied nurses had a good level of knowledge, while less than one third $(33.9 \%)$ of them had an average level and the lowest percentage $18.6 \%$ had a poor level with mean \pm SD $17.12 \pm 1.74$.

Figure (2): Illustrates the level of practice of studied nurses provided for neonates on mechanical ventilation. It was found that more than one third (39\%) of them had a good level of practice and $(37.3 \%)$ of them had average level while the lowest percentage $23.7 \%$ of them had a poor level with mean \pm SD $185.59 \pm 20.35$.

Figure (3): Demonstrates there was no statistically significant difference between the total score of the studied nurses ' level of knowledge and practice (p. value $=0.285$ ).

\section{Discussion}

Nurses caring for neonates on mechanical ventilation faced numerous challenges. Expertise and extreme care are significant aspects in providing safe and effective nursing care to improve the quality of nursing care provided for them in order to raise the survival rate for these neonates, decrease morbidity and mortality rates. They also must provide a safe environment for these neonates in the unit and follow the infection control policies. Rocha et al., (2018).
As regards the nurses' knowledge about the quality of nursing care for neonates on mechanical ventilation. The present study found that less than half of the studied nurses had a good level of knowledge; this results supported by Ahmed., (2014) who found that more than half of the studied nurses had correct knowledge regarding promoting quality of care, while this finding was dissimilar with Mohammed, (2012) who found that nurses had an average level of knowledge related to nursing care of neonates on mechanical ventilation.

Regarding nurses' practice about the quality of nursing care provided for neonates on mechanical ventilation. The current study revealed that more than one-third of the studied nurses had a good level of practice, this finding disagrees with Shahin et al., (2013) who found that more than two-thirds of the studied nurses had a poor level of total practice score. The present study revealed that there was a statistically significant relationship between nurses' level of knowledge and their residence, this finding agrees with Mansi et al., (2017) who found that there was statistically significant relation between nurses' level of knowledge and their residence. This is because of more than two-thirds of them from rural areas.

The present study viewed that, there was a positive relation between the studied nurses' total knowledge score and their qualification $(\mathrm{p}<0.034)$. This finding was consistent with the finding of the study done by Abdel-Fattah, (2018) who found that there was statistically significant relation between nurses' knowledge and qualifications, this finding disagrees with Ahmed, (2014) who reported that there was no statistically significant relation between nurses' knowledge and qualifications. This result may be due to more than half of the studied nurses had a diploma of nursing.

The finding of the present study showed that there was a statistically significant difference between the nurses' level of knowledge and years of experience. This finding was supported by Zaki, (2018) who found that there was a statistically significant difference between nurses' level of knowledge and years of experience. This finding contradicts with that of Abdel Halim, (2013) who stated that there was no statistical difference between nurses' level of knowledge and years of experience. This may be explained that nurses had more and updating knowledge along years of experience.

The finding of the present study illustrated that there was a statistically significant relation between nurses' level of practice and marital status. This finding contradicts with that of Ahmed, (2014) who found that there was no statistically significant relation between nurses' level of practice and marital status. 
This because more than half of the studied nurses are ever married.

The current study illustrated that there was a statistically significant relation between nurses' level of practice and qualifications. This finding in the same line with Zaki et al., (2018) who found that there was a statistically significant difference between nurses' total practice score and their qualifications. This result may be due to more than half of the studied nurses had a diploma of nursing. Regarding relationship between nurses' level of practice and years of experiences, the current study showed that, there was a statistically significant relation between nurses' level of practice and years of experience, this finding goes on the same line with Ahmed, (2014) who found that, there were statistically significant relation between total nurses' practice and years of experiences. This finding dissimilar with Abou Ahmed, (2013) who found that there was no relation between nurses' practice and year of experiences. Actually, years of experience enable them to master skills competently. There were no statistically significant differences between the total score of the studied nurses' level of knowledge and practice. This finding was in the same line with Sayed, (2009) in his article about "assessment of the quality of nursing care given for high-risk neonate" who reported that there was no statistically significant difference between total scores of nurses' level of knowledge and practice. This finding was in contrast to Mohamed, (2012) who found that there was a highly statistically significant difference between the nurses' knowledge regarding mechanical ventilation and their role in the care of neonates undergoing mechanical ventilation.

\section{Conclusion}

Based on the results of the present study, it can be concluded that; about less than half of the studied nurses had a good level of knowledge and practice. There were no statistically significant differences between total scores of the studied nurses' level of knowledge and practice regarding the quality of nursing care for neonates on mechanical ventilation.

\section{Recommendations}

Based on the results of the present study the following recommendations can be suggested:

1- Periodical educational training programs for nurses working at NICU are mandatory, for the purpose of raising and updating the knowledge for nurses'.

2- Nurses' attendance of films and audiovisual conferences about practical procedures to increase their awareness with the recent approaches.

3- Manual handbooks containing all essential information about nursing procedures should be available at the unit.

\section{References}

1. Abdel-Fattah N., Shafik Fand Mostafa S., (2018): quality of nurses' performance regarding parenteral nutrition at neonatal intensive care units, Egyptian Journal of Health Care, Vol (9), No (2), Pp: 116-28.

2. Abdel-Halim F., (2013): Nursing intervention for neonatal infection: An assessment study, (master degree) Egypt, Faculty on nursing, Ain Shams University, Pp: 45-81.

3. Abou- Ahmed., (2013): compliance of nurses with neonatal care protocol regarding feeding in neonates, unpublished thesis (master degree) Egypt, Faculty of nursing, Ain Shams University, Pp: 59-66.

4. Ahmed R., Mohamed A., \& Mahmoud F., (2014): Quality of nursing care provided for neonates with tracheoesophageal fistula, Journal of education and practice, Vol (5), No (3), Pp: 186-99.

5. American Nurses Association, (2010): Standards of Clinical Nursing Practice, $3^{\text {rd }}$ edition, Mokansas city. Pp: 145-49.

6. Aurora M., Kopek K., Weiner G., \& Donn S., (2017): Basics of infant conventional mechanical ventilation, the journal of teaching and learning resources. Vol (48), No (4), Pp:481-49.

Available

at: https://doi.org/10.15766/mep_23748265.10658.

7. Haruzivishe C., Mhlanga M., Ndaimani A., \& Zvinavashe A., (2016): Quality Nursing Care: A concept analysis, Journal of Medical and Dental Science Research, Vol (3), No (1), Pp: 27.

8. Kalia. R., (2015): pediatric nursing procedures, chapter 36: care of a baby on a ventilator, $2^{\text {nd }} \mathrm{ed}$, New Delhi, Japee Brothers Medical Publishers (p) Ltd, Pp: $116-23$.

9. Mansi Q., \& Aziz A., (2017): Assessment Nursing Care in Neonatal Respiratory Distress Syndrome for Nurses at Intensive Care Unit, International Journal of Science and Research, Vol(6), Issue(5), Pp:550- 53.

10. Mohamed A., (2012): Quality of Nursing Care for Neonate Undergoing Mechanical Ventilation at Benha city, Master Degree, Faculty of Nursing, Benha University, Egypt, Vol (57), No (5), Pp:782-88. 
11. Rocha G., Soares P., Silva A., \& Almeida D., (2018): Respiratory Care for the Ventilated Neonate, Canadian Respiratory Journal, Pp:112.

Available

at https://doi.org/10.1155/2018/7472964

12. Sabzeie M., Sabouri T., Sokri M., \& Basiri B., (2016): The Study of Pulmonary Complication of Neonatal Mechanical Ventilation in NICU, Scientific Journal of Hamadan University of Medical Sciences, Vol (22), Issue(4), Pp: 269-75.

13. URL: http://sjh.umsha.ac.ir/article-1-553en.html.

14. Sayed H., (2009): Assessment of quality of nursing care given for high-risk neonate (master degree) Egypt, Faculty on nursing, Ain Shams University, Pp: 62-71.

15. Shahin V., Warre R., \& Klee S., (2013): Quality Improvement Initiatives in Neonatal Intensive Care Units: Achievements and Challenges, Journal of Quality, Vol (13), No (75), Pp: 25-40.

16. Taksande A., (2014): practical aspects of pediatrics and neonatology for nurses, Chapter 19: common bedside equipment, $1^{\text {st }}$ ed, New Delhi, Japee Brothers Medical Publishers (p) Ltd, Pp: 94-95, 170.

17. Zaki A., El-Sayed E., Said K., \& Ali A., (2018): assessment of nurses' performance regarding care for neonates with necrotizing enterocolitis at intensive care units, Egyptian Journal of Health Care, Vol (9), No(3), Pp:11124. 